\title{
Morphophysiological and molecular characterization of millet (Panicum miliaceum L.) varieties for crop improvement in Western Europe
}

\author{
Massimo Vischi ${ }^{1}$ Nicola Zorzin ${ }^{1}$, Maria Bernhart ${ }^{2}$, Johanna Winkler ${ }^{2}$, Dipak Santra ${ }^{3}$, Carla Pappalardo ${ }^{1}$ and
} Stefano Marchetti ${ }^{{ }^{*} \text { (B) }}$

\begin{abstract}
Background: Global warming and issues in favour of a more sustainable agriculture suggest a reconsideration of minor cereals in European agrosystems. Compared to other summer crops, proso millet has a remarkable drought resistance and could be used to improve crop rotation and biodiversity. Proso millet is also increasingly sought by industry to produce novel foods such as those designed for coeliac patients. In this study, a thorough characterization of 11, commercially available, proso millet (Panicum miliaceum L.) varieties was carried out as a preliminary step for crop reintroduction and breeding in Western Europe.

Methods: The cultivars under evaluation were introduced from Austria, Poland, Russia, and the USA (University of Nebraska-Lincoln). Plants were grown at Udine (NE Italy) and Gleisdorf (Styria, Austria), under greenhouse and field conditions, respectively. Yield components and a range of morphophysiological characters were recorded in both locations. In parallel, 85 SSR markers were tested on DNA samples extracted from randomly chosen plants of each variety and the 12 responsive markers used to genotype the whole variety set.

Results: Morphometric analyses showed that varieties have several diverging phenotypic traits and architectures. In all instances, yields recorded at field level were much lower than potential yields. In this respect, US selections were comparable to earlier developed European varieties, suggesting that breeding for an increased adaptation is the keystone for a stable reintroduction of millet in Western Europe. Molecular analyses uncovered remarkably low genetic differences and heterozygosity levels within cultivars, confirming millet as an essentially autogamous species; in contrast, large genetic distances were noted among cultivars selected in different environments. Results of SSR genotyping combined with those originating from phenotypic analyses indicated possible crosses to source the genetic variability necessary for selection.
\end{abstract}

Conclusions: This study enabled the identification of cultivars that could be used to revitalize the crop in Western Europe and to produce genetically variable hybrid progenies exploitable by breeding.

Keywords: Panicum miliaceum, Proso millet, Varietal characterization, SSR genotyping

*Correspondence: stefano.marchetti@uniud.it

${ }^{1}$ Di4A, University of Udine, Via delle Scienze 206, 33100 Udine, Italy

Full list of author information is available at the end of the article

\section{Background}

Proso millet (Panicum miliaceum L.) is a minor cereal whose main characteristics are the short life cycle and the remarkable heat and drought resistance. It is a traditional

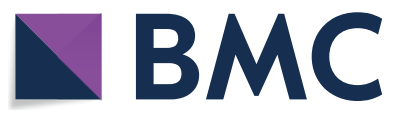

(c) The Author(s) 2021. This article is licensed under a Creative Commons Attribution 4.0 International License, which permits use, sharing, adaptation, distribution and reproduction in any medium or format, as long as you give appropriate credit to the original author(s) and the source, provide a link to the Creative Commons licence, and indicate if changes were made. The images or other third party material in this article are included in the article's Creative Commons licence, unless indicated otherwise in a credit line to the material. If material is not included in the article's Creative Commons licence and your intended use is not permitted by statutory regulation or exceeds the permitted use, you will need to obtain permission directly from the copyright holder. To view a copy of this licence, visit http://creativeco mmons.org/licenses/by/4.0/. The Creative Commons Public Domain Dedication waiver (http://creativecommons.org/publicdomain/ zero/1.0/) applies to the data made available in this article, unless otherwise stated in a credit line to the data. 
crop cultivated in summer after a winter cereal or a meadow grass, especially in hot, arid and semi-arid regions of Eurasia and Africa (Habiyaremye et al. 2017a). Proso millet was domesticated $8000-10,000$ years ago in East Asia (Lu et al. 2009) as one of the earliest dry crops. It was introduced into Western Europe during the Late Middle Ages from Eastern Europe and the Middle East, but its subsequent diffusion ceased abruptly after the introduction of maize and potato from the Americas; millet decline prolonged over time due to the preference of farmers for more profitable summer crops.

Currently, Western Europe has very limited surfaces with millet, which is grown mainly as a forage crop or a grain crop for animal (essentially bird) feed; even in marginal lands or under low-input systems, it is barely used in crop rotations designed to control weeds and preserve deep soil moisture (Habiyaremye et al. 2017a). Nevertheless, in recent times a trend has been recorded in human diet diversification (Fanzo et al. 2013; Dwivedi et al. 2017) and the spread of food recipes naturally enriched in nutritional elements has raised the interest of consumers and food industries in proso millet as well as other minor cereals (Das et al. 2019).

Proso millet is a tetraploid species with 36 chromosomes, originated from the interspecific cross between $P$. capillare (or a close relative with $2 \mathrm{n}=18$ ) and $P$. repens $(2 n=18)$ (Hunt et al. 2014); genome sequencing and contig assembly in 18 pseudochromosomes have been recently reported (Zou et al. 2019). The tetraploid nature of proso millet in conjunction with a relative paucity of robust molecular markers has hindered genetic analysis of the species; often, a significant portion of the markers available in the literature had to be discarded due to lack of amplification, unreliable scoring, monomorphism, or stuttering (Hunt et al. 2011). Little information is also available on the level of autogamy/allogamy and on artificial crossing techniques. Based on floral morphology, timing of anther dehiscence and lack of inbreeding depression, proso millet is considered an autogamous species; it should be noted however that outcrossing rates as high as 10\% were reported (Gupta et al. 2012 and references herein). Whether outcrossing is similarly occurring in landraces and modern cultivars is basically unknown.

Conversely, more data are existing on the chemical and biochemical composition of millet seeds promoting its use as a human food. Compared to wheat, the introduction of proso flour in a diet can improve protein supply, mineral nutrition and vitamin intake (Kalinová and Moudry 2006). Moreover, proso millet is devoid of any trace of gluten and can therefore be consumed by people suffering from coeliac disease (Rai et al. 2018; Das et al. 2019). Additionally, millet seeds contain a range of phytochemicals known to prevent or reduce the risk of type-2 diabetes mellitus, cardiovascular diseases and age-onset degenerative diseases (Pathak 2013; Saleh et al. 2013). Differently from pearl millet and other small millets, proso seeds do not contain C-glycosylflavones with goitrogenic effect (Kalinová 2007). All nutritional components are present in variable amounts according to genotype (Vetriventhan and Upadhyaya 2018). Similarly, morphological traits affecting quality are under strict genetic control (Trivedi et al. 2015), as demonstrated also by estimates of broad heritability indexes (Vetriventhan and Upadhyaya 2018). Conceivably, a reintroduction of millet in Western Europe will be achieved only after the completion of multilocation agronomic trials carried out on commercially available varieties and, hopefully, the development of a new set of cultivars with an improved adaptability, flour quality and yield. This initiative could be supported by the Agricultural Knowledge and Innovation Systems (AKIS) developed by EU Member States to strengthen advisory services for a more sustainable and resilient agriculture (Klerkx 2020).

In this study, with the aim of identifying suitable parents for crossing and breeding, several proso millet varieties currently cultivated in Eastern Europe and the US were morphologically characterized using a range of descriptors defined for P. miliaceum and P. sumatrense (IBPGR 1985). For the same purpose, the genetic diversity among and within varieties was assessed with molecular markers. In particular, SSRs were chosen because they are co-dominant and generally highly informative; furthermore, their determination is rapid and relatively economical (Vieira et al. 2016).

\section{Materials and methods}

\section{Plant introduction and cultivation}

To relaunch millet ( $P$. miliaceum L.) cultivation in northern Italy and southern Austria, 11 varieties from different countries (Table 1) were introduced in compliance with international rules on cultivated germplasm transfer. All varieties were tested in a greenhouse at Udine (Italy) and under open-field conditions at Gleisdorf (Austria) during 2017. They were also cultivated in 2018 essentially for refinement of molecular testing and the production of hybrid seed through manual crossing.

Inside greenhouse, single plants were grown in $23-\mathrm{cm}$ pots containing $7 \mathrm{~L}$ of pre-manured Compo Universal substrate (Compo Italia srl); they were irrigated 2-3 times a week with a drip system until soil water capacity was reached. Temperature was kept between $18^{\circ}$ and $30{ }^{\circ} \mathrm{C}$ with a warming and cooling system; relative humidity ranged between 65 and $88 \%$. Each variety was sown on May 23rd, 2017 in 40 pots at a rate of 3 seeds per pot; to ensure maximum growth and uniformity, excess 
Table 1 List of P. miliaceum varieties used in this study

\begin{tabular}{lll}
\hline Variety & Abbreviations & Selection site \\
\hline Kornberger & Kbg & Austria (Saatzucht Gleisdorf) \\
Lisa & Ls & Austria (Saatzucht Gleisdorf) \\
GL RH16106 & Glr & Austria (Saatzucht Gleisdorf) \\
Quartett & Qrt & Russia \\
Tiroler & Trl & Austria \\
Jagna White & JWt & Poland \\
Earlybird & Ebr & USA (University of Nebraska-Lincoln) \\
Sunrise & Snr & USA (University of Nebraska-Lincoln) \\
Sunup & Snp & USA (University of Nebraska-Lincoln) \\
Horizon & $\mathrm{Hrz}$ & USA (University of Nebraska-Lincoln) \\
Huntsman & $\mathrm{Hnt}$ & USA (University of Nebraska-Lincoln) \\
\hline
\end{tabular}

plants were thinned at the two-leaf stage. No manure or pesticides were applied.

Additional 40 plants per variety were grown under open-field conditions on a pseudogley (a soil type constituted by brown earth and sandy loam) near the Saatzucht Gleisdorf Ges.mbH headquarters. Millets were sown on July 14th, 2017 in adjacent 6-m rows with a row spacing and a distance between plants in a row of 80 and $15 \mathrm{~cm}$, respectively. Twice the required number of seed was used to obtain a uniform layout after subsequent manual thinning. The experimental plot was bordered with a homozygous line selected by the company. No manures or pesticides were applied, and no irrigation was performed. Plants grew under climate conditions typical of the Illyrian region (a sub-alpine transitional area subject to the influences of the Mediterranean Sea). Meteorological data were recorded and are available upon request.

\section{Morphometric analyses}

To characterize millet varieties from a morphological and physiological point of view, we referred to the IBPGR descriptors (IBPGR 1985) reported in Table 2. All descriptors plus 1000-seed weight and seed production/plant were measured in both locations according to standard practice. As indicated by IBPGR, plant height and culm length can differ due to lodging, or to a decumbent/prostrate habit; to better depict the outcomes achieved in the two environments, culm length of every variety is reported in conjunction with information on growth habit and lodging susceptibility. Care was taken to prevent plant damage during data collection. All 40 plants grown in the greenhouse were evaluated, whereas 10 plants in the central part of the row were considered in the case of field cultivation. Harvest was carried out manually. Due to the presence of extremely favourable growth conditions in the greenhouse, seed production/
Table 2 IBPGR descriptors used for morphophysiological characterization

\begin{tabular}{ll}
\hline IBPGR reference & Descriptor \\
\hline 4.1 .1 & Growth habit at flowering \\
4.1 .2 & Plant height (Culm length) \\
4.1 .3 & Plant pigmentation at flowering \\
4.1 .4 & Number of basal tillers \\
4.1 .5 & Number of culm branches \\
4.1 .6 & Flag leaf blade length \\
4.1 .7 & Flag leaf blade width \\
4.1 .8 & Blade pubescence \\
4.1 .9 & Flag leaf sheath length \\
4.1 .10 & Sheath pubescence \\
4.1 .12 & Degree of lodging at maturity \\
4.1 .13 & Senescence \\
4.2 .1 & Peduncle length \\
4.2 .2 & Peduncle exertion \\
4.2 .3 & Inflorescence length \\
4.2 .4 & Number of primary inflorescence branches \\
4.2 .5 & Number of nodes on primary inflorescence axes \\
4.2 .6 & Number of secondary inflorescence branches \\
4.2 .7 & Inflorescence shape \\
4.2 .8 & Inflorescence compactness \\
4.2 .9 & Fruit colour \\
4.2 .10 & Apiculus pigmentation \\
4.2 .13 & Flowering date \\
5.5 & Harvest date \\
6.2 .1 & Individual plant uniformity at maturity \\
6.2 .2 & Shattering of inflorescence \\
6.3 .5 & \\
\hline &
\end{tabular}

plant obtained in this environment was retained a good estimate of the yield potential of a variety.

Morphometric data of a quantitative nature were submitted to one-way analysis of variance, each plant representing a replicate; varietal means were compared with the multiple Duncan's range test at a probability level $\mathrm{P}=0.05$. The predictability of on-farm production on the basis of yield potentials (as determined under controlled, greenhouse conditions) was estimated through standard correlation analysis.

\section{Sample collection, DNA extraction and SSR genotyping}

Three weeks after emergence, tissue samples were collected from all greenhouse-grown plants. Each sample, consisting of a young leaf tip, was individually introduced into a $2 \mathrm{~mL}$ Eppendorf tube, immediately frozen in liquid nitrogen and stored at $-80{ }^{\circ} \mathrm{C}$ until analysis. For each variety on trial, total DNA was extracted from 10 randomly chosen samples making use of the DNeasy 
${ }^{\mathrm{TM}}$ Plant Mini Kit (Qiagen) according to manufacturer's instructions.

A total of 85 SSR loci successfully used in previous works on millet (Hu et al. 2009; Cho et al. 2010; Hou et al. 2017) were tested on DNA extracts obtained from the greenhouse-grown plants. Following the tests, 12 primer couples were chosen on the grounds of their Tm, length, and degree of polymorphism. The list of the selected primer couples is reported in Table 3. Forward primers were tailed by adding a 19-mer M13 oligo sequence (M13 tail) at their $5^{\prime}$ end. Oligonucleotides consisting of only the M13 tail sequence labelled with FAM or HEX were used as reporters. The principle of the procedure is as follows: in the first few cycles of amplification, the M13-forward primers produce amplicons with the M13 sequence integrated at their $5^{\prime}$ end. Afterwards, the reporters, being present in the solution at a much higher concentration, pair with the amplicons instead of the forward primers, and function as forward primers for the remaining cycles, thus producing labelled amplicons. Hence, this procedure enables to use a single, universal reporter instead of as many labelled primers as primer couples (Schuelke 2000; Boutin-Ganache et al. 2001; Fukatsu et al. 2005). The PCR reaction was performed in $10 \mu \mathrm{L}$ of a solution containing $10 \mathrm{ng}$ genomic DNA, $1 \times$ Wonder Taq Hot Start Reaction buffer (Euroclone), 0.1 pmol M13-forward primer, 0.3 pmol labelled M13 primer acting in forward, $0.3 \mathrm{pmol}$ reverse primer, $0.5 \mathrm{U}$ Wonder Taq Hot Start (Euroclone) and $\mathrm{dH}_{2} \mathrm{O}$. Amplification was performed in a T-100 Thermal Cycler (Bio-Rad) as follows: $3 \mathrm{~min}$ at $95^{\circ} \mathrm{C}, 25$ cycles of: $15 \mathrm{~s}$ at $95^{\circ} \mathrm{C}, 15 \mathrm{~s}$ at $55{ }^{\circ} \mathrm{C}, 30 \mathrm{~s}$ at $72{ }^{\circ} \mathrm{C}, 10$ cycles of: $15 \mathrm{~s}$ at $95{ }^{\circ} \mathrm{C}, 15 \mathrm{~s}$ at $53{ }^{\circ} \mathrm{C}, 30 \mathrm{~s}$ at $72{ }^{\circ} \mathrm{C}$ and a final extension step of $15 \mathrm{~min}$ at $72{ }^{\circ} \mathrm{C}$. PCR products were separated with an ABI 3730
DNA sequencer (Applied Biosystems) and the fragments were sized by means of a ladder labelled with a VIZ fluorochrome (LIZ500 Applied Biosystems).

Molecular data were used for the assessment of genetic variation and for distance-bases clustering. For each SSR locus, the allelic data obtained from GeneMarker software (Version 2.7.0, SoftGenetics) were elaborated with the PowerMarker v3.25 (Liu and Muse 2005) to estimate diversity parameters, including the number of alleles $(\mathrm{N})$, major allele frequency (MAF), observed heterozygosity (Het), expected heterozygosity/gene diversity (GD) and polymorphism information content (PIC). The neutrality of selected loci was checked with the Ewens-Watterson test (1000 permutations) using PopGene software (Yeh et al. 1997). Genotypic distance matrixes of pairwise combinations of populations and single accessions were calculated for codominant data by the Codom-Genotypic distance option in GenAlEx 6.1 software (Peakall and Smouse 2006). The matrixes generated were used for subsequent AMOVA (999 permutations) analyses. Cluster analysis was conducted on genetic distances by the unweighted pair-group method using arithmetic averages (UPGMA). The MEGA 6 software of Tamura et al. (2013) was applied for the purpose.

\section{Results and discussion \\ Varietal differences in morphometric traits}

Proso millet is widely recognized as an adaptable species, capable to grow with minimal agronomic input in hot and dry climates where harsh conditions discourage farmers to undertake the cultivation of other summer crops (Bandyopadhyay et al. 2017; Saxena et al. 2018). Resilience to environmental stresses is accomplished by changes on yield components and physiologically related

Table 3 Primer couples selected for the study

\begin{tabular}{|c|c|c|c|c|}
\hline Locus & Primer forward sequence & Primer reverse sequence & Repeat motif & N. of alleles \\
\hline PMM-014 & GGGAGACGCAGTGTGGTA & TACAGGTCCTGCGTGAGG & (CGT)3(CAT)(CGT)5 & 4 \\
\hline PMM-023 ${ }^{\mathrm{a}}$ & GCTAGCTTGTTGTTGCCG & GATGCGTACCGCTTGTGT & $(G A) 19$ & 7 \\
\hline PMM-066 ${ }^{\mathrm{a}}$ & TAATGCCAAACCAAGCGT & GGTACAAGTACAAGCCCGC & $(\mathrm{TGC}) 6$ & 3 \\
\hline PMM-073a & GCTCTCACCGTCTGATCG & CGCATTCTCTTCCCCTTT & (TC)21(CGTG)4 & 9 \\
\hline$P M M-106^{a}$ & AGCGAGAGGAAACAGCGT & ATAGGCGTCGGAGATGGT & (TC)19 & 6 \\
\hline PMM-115 & GCACGTCACACTCACACG & TGGGTGTATCAGGGCTTG & $(\mathrm{AG}) 15$ & 6 \\
\hline PMM-121 ${ }^{\mathrm{a}}$ & GGACATACGCATGGTGGT & ACGATCGAATGAGCGAGA & (AT)7(GTAT)9 & 6 \\
\hline$P M M-126^{a}$ & CTTCCATAGGGTGCCTCC & CATCGCAATTGGGAAAGA & $(G A A) 5(G A) 20$ & 8 \\
\hline PMM-134 & CAGGCTCTGGCAAAGATG & CAAGGTCAGGGGAACCAT & $(\mathrm{AG}) 22$ & 11 \\
\hline $\operatorname{SXAU} 32^{\mathrm{b}}$ & GGTACAGCCGGGAGGACTAC & TAGGAGGAGCAAACTGCTGG & (GGC)6 & 4 \\
\hline SXAU95 ${ }^{b}$ & AGCATCCAGCACAAGGTCTC & CTCACTCCAGCAACTGGTCA & (GCG)6 & 3 \\
\hline SXAU227 & ACATCCATCGGAAAGCTACG & ATGTCCGATCAAACCTCACC & (GCGAT) & 3 \\
\hline
\end{tabular}

${ }^{a}$ Cho et al. (2010)

${ }^{b}$ Hou et al. (2017) 


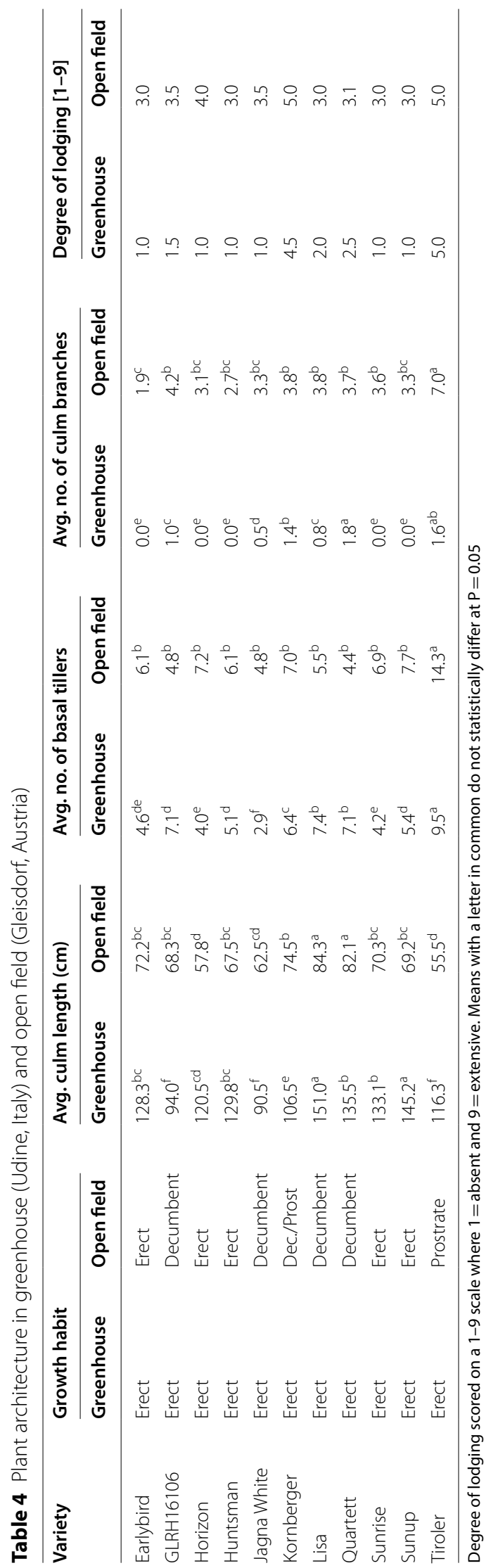


traits. Seghatoleslami et al. (2008) found that water deficit at the flowering stage induces a re-planning of the reproductive phase involving a reduction of seed set and seed weight; drought stress applied at the seed-filling stage or during vegetative growth had comparably a lower impact on water use efficiency, panicle number/plant, floret fertility and seed yield. On the other hand, tolerance to adverse conditions is expressed at different levels across genotypes and genotypes can display variable responses under different conditions, as demonstrated by significant interactions with environment observed in multi-location or multi-year trials (Vetriventhan and Upadhyaya 2018; Flajšman et al. 2019). While several data were collected on landraces to detect the morphological and physiological traits mostly associated to yield (Salini et al. 2010; Upadhyaya et al. 2011; Vetriventhan and Upadhyaya 2018; Zhang et al. 2019; Calamai et al. 2020), little information is available on yield potential and the associated morphological traits shown by different genotypes when grown under optimal conditions. Such information is relevant to properly assess the genetic variability existing in millet varieties and to ascertain the phenotypic modifications implemented by plants to cope with high temperatures and drought. In our opinion, this would facilitate the choice of parental lines for crossing and better address selection activities. With this aim, we compared a set of 11 commercially available cultivars, currently cultivated in Western Europe or USA, under field conditions in summer and undumped greenhouse conditions in mid-Spring. Especially in the greenhouse, the level of uniformity within varieties was remarkably high and this contributed to a clear varietal differentiation according to more IBPGR descriptors. As expected, some parameters (e.g., growth habit, lodging resistance) were better evaluated in the field whereas others (notably yield potential) could be defined only under an optimal growth regime.

\section{Plant architecture}

Significant intervarietal differences were noted in growth habit, culm length, tillering, branching on the main stem, blade length and width (flag leaf). In particular, greenhouse-grown millets always showed an erect phenotype at flowering with some lodging observed only towards physiological maturity, mostly as a consequence of an increased panicle weight. Interestingly, lodging was unrelated to culm length but affected by tillering and branching on the main stem (Table 4). Varieties from the USA developed by the University of Nebraska-Lincoln (hereinafter, US varieties) did not branch the main culm and produced significantly fewer tillers in comparison with varieties currently grown and developed in Europe (hereinafter, EU cultivars). Under open-field conditions, plants of all varieties had a shorter stem and a much greater tendency to form culm branches. Despite a more compact, bushy phenotype, the growth habit at flowering was prostrate or decumbent in all EU cultivars and the degree of lodging at maturity was significantly higher. It should be noted that erect growth at flowering, typical of US varieties, was accompanied by lower lodging at maturity. Again, no correlation was found between lodging susceptibility and culm length; it should be noted however that the height of field-grown varieties was always less than $90 \mathrm{~cm}$, a value usually adequate for standability of millet plants (Zhang et al. 2019).

A further trait differentiating the cultivars on trial was the shape and overall dimensions of the leaf blade. To take into account possible differences in plant leafiness, IBPGR descriptors consider the blade length and width of the flag leaf. In both environments, US varieties mostly had significantly longer and wider leaves as compared to EU cultivars (Table 5); within the latter group, a greater variability was recorded, with Tiroler at the lowest edge for both parameters. Despite leaf area being nearly halved in open field conditions, ranking of the cultivars was relatively similar in the two environments except for Kornberger, a variety that showed a minimal reduction of leaf blade when grown in the field. The maintenance of an expanded leaf apparatus under moderate stress conditions appears particularly important for millet, as the efficiency of its $\mathrm{C}_{4}$ carbon fixation system is maximized at warm temperatures; the high radiation use efficiency (which in $\mathrm{C}_{4}$ species is associated to a high water- and nitrogen use efficiency; Sage and Zhu 2011) is important to accelerate root and canopy development for the shortening of life cycle (Bandyopadhyay et al. 2017). In line with this evidence, the possibility for the plant to establish a good leaf apparatus soon after emergence was found essential to display acclimation and drought resistance at later developmental stages (Habiyaremye et al. 2017b).

\section{Inflorescence, time of flowering, and duration of the reproductive phase}

In conjunction with inflorescence shape and plant architecture, peduncle exertion influenced the overall morphology of millet varieties. Especially in the greenhouse, significant differences were noted in this character, with US varieties consistently showing lower values (Table 5 ). Interestingly, in field-grown varieties peduncle exertion did not decrease proportionally to culm length, indicating a distinct inheritance and therefore the possibility of an independent selection for this trait. Furthermore, peduncle exertion was also unrelated to panicle shape and seed yield per plant. Vetriventhan and Upadhyaya (2018) noted that panicle exertion remarkably differs in 
Table 5 Leaf size, panicle shape and exertion in greenhouse (Udine, Italy) and open field (Gleisdorf, Austria)

\begin{tabular}{|c|c|c|c|c|c|c|c|c|}
\hline \multirow[t]{2}{*}{ Variety } & \multicolumn{2}{|c|}{ Avg. leaf length (mm) } & \multicolumn{2}{|c|}{ Avg. leaf width (mm) } & \multicolumn{2}{|c|}{ Avg. peduncle exertion $(\mathrm{mm})$} & \multicolumn{2}{|c|}{ Inflorescence shape } \\
\hline & Greenhouse & Open field & Greenhouse & Open field & Greenhouse & Open field & Greenhouse & Open field \\
\hline Earlybird & $449.8^{b}$ & $224.0^{\mathrm{a}}$ & $30.3^{\mathrm{ac}}$ & $23.0^{\mathrm{b}}$ & $103.0^{\mathrm{de}}$ & $59.0^{f}$ & Globose & Globose \\
\hline GLRH16106 & $334.6^{d}$ & $238.1^{\mathrm{a}}$ & $27.5^{\mathrm{cd}}$ & $23.9^{b}$ & $184.8^{c}$ & $186.5^{\mathrm{bc}}$ & Arched & Arched \\
\hline Horizon & $404.5^{c}$ & $234.0^{\mathrm{a}}$ & $29.2^{b c}$ & $23.6^{b}$ & $79.8^{e}$ & $105.7^{\text {def }}$ & Arched & Arched \\
\hline Huntsman & $517.3^{\mathrm{a}}$ & $275.0^{\mathrm{a}}$ & $31.3^{\mathrm{ab}}$ & $25.4^{b}$ & $121.9^{\text {de }}$ & $79.7^{\text {ef }}$ & Arched & Globose \\
\hline Jagna White & $357.3^{d}$ & $220.0^{\mathrm{a}}$ & $24.1^{\mathrm{e}}$ & $23.1^{b}$ & $123.1^{\text {de }}$ & $146.6^{\mathrm{cd}}$ & Globose & Globose \\
\hline Kornberger & $336.6^{d}$ & $264.6^{\mathrm{a}}$ & $21.6^{\mathrm{e}}$ & $23.1^{b}$ & $274.1^{\mathrm{ab}}$ & $282.2^{\mathrm{a}}$ & Arched & Arched \\
\hline Lisa & $434.0^{b c}$ & $255.8^{\mathrm{a}}$ & $23.7^{e}$ & $21.8^{\mathrm{b}}$ & $137.2^{d}$ & $158.5^{\mathrm{bcd}}$ & Globose & Diffuse \\
\hline Quartett & $346.5^{d}$ & $238.3^{\mathrm{a}}$ & $26.3^{d}$ & $22.1^{b}$ & $303.1^{\mathrm{a}}$ & $211.5^{b}$ & Diffuse & Diffuse \\
\hline Sunrise & $466.4^{b}$ & $264.1^{\mathrm{a}}$ & $30.1^{\mathrm{ac}}$ & $26.2^{\mathrm{ab}}$ & $95.8^{\text {de }}$ & $133.7^{\text {cde }}$ & Globose & Globose \\
\hline Sunup & $445.8^{b}$ & $282.4^{\mathrm{a}}$ & $32.7^{\mathrm{a}}$ & $29.3^{\mathrm{a}}$ & $81.7^{e}$ & $84.8^{\mathrm{ef}}$ & Arched & Globose \\
\hline Tiroler & $271.0^{\mathrm{e}}$ & $124.3^{b}$ & $14.5^{f}$ & $12.3^{c}$ & $246.2^{b}$ & $182.9^{b c}$ & Arched & Arched \\
\hline
\end{tabular}

Means with a letter in common do not statistically differ at $\mathrm{P}=0.05$

ICRISAT accessions but, differently from most quantitative characters, no significant genotype $\times$ environment interaction could be detected for this trait; instead, a significant negative correlation between yield and peduncle length or exertion was uncovered. Notwithstanding this fact, the influence of the latter parameters on yield remains uncertain, as in former work (Upadhyaya et al. 2011) they were found positively associated with both earliness and plant height, i.e., two traits which were respectively indicated as detrimental and favourable for yield (Salini et al. 2010; Zhang et al. 2019; Calamai et al. 2020).

The combination of culm length, peduncle exertion and panicle shape gave rise to different morphotypes such as those of Lisa (long stem, short peduncle, globose/diffuse panicle), Quartett (long stem, long peduncle, diffuse panicle) and Tiroler (short stem, long peduncle, arched panicle). Additional morphotypes were formed by the degree of tillering, culm branching and leaf dimensions (e.g., Sunup: long stem, short peduncle, arched panicle, reduced tillering and stem branching, large leaves). Some morphotype deviations involving panicle shape occurred in a few cultivars when grown in the field, but their overall impact on plant structure was limited.

An important varietal differentiating factor was the level of earliness in flowering and maturity (Table 6). In both environments, US varieties were the last to head the panicle and ripen the seeds. However, the behaviour of millet varieties in the greenhouse and the field was remarkably different. Contrary to expectations, under

Table 6 Life cycle data in greenhouse (Udine, Italy) and open field (Gleisdorf, Austria)

\begin{tabular}{|c|c|c|c|c|c|c|c|c|}
\hline \multirow[t]{2}{*}{ Variety } & \multicolumn{2}{|c|}{ Senescence [1-9] } & \multicolumn{2}{|c|}{ Days to flowering } & \multicolumn{2}{|c|}{ Days to harvest } & \multicolumn{2}{|c|}{ Uniformity of maturity (\%) } \\
\hline & Greenhouse & Open field & Greenhouse & Open field & Greenhouse & Open field & Greenhouse & Open field \\
\hline Earlybird & 2 & 8 & 48 & 43 & 97 & 111 & 100 & 100 \\
\hline GLRH16106 & 3.5 & 7 & 32 & 36 & 69 & 89 & 94 & 98 \\
\hline Horizon & 1.5 & 8 & 48 & 41 & 101 & 111 & 90 & 100 \\
\hline Huntsman & 3 & 8 & 42 & 43 & 97 & 111 & 98 & 100 \\
\hline Jagna White & 3 & 7 & 33 & 41 & 71 & 98 & 100 & 95 \\
\hline Kornberger & 4.5 & 7 & 30 & 36 & 65 & 89 & 98 & 98 \\
\hline Lisa & 5 & 6 & 33 & 39 & 65 & 97 & 100 & 95 \\
\hline Quartett & 6 & 6 & 18 & 37 & 58 & 97 & 100 & 98 \\
\hline Sunrise & 2.5 & 8 & 48 & 42 & 97 & 111 & 95 & 100 \\
\hline Sunup & 4 & 8 & 48 & 45 & 99 & 111 & 100 & 100 \\
\hline Tiroler & 5.5 & 7 & 19 & 33 & 62 & 89 & 100 & 98 \\
\hline
\end{tabular}

Plant senescence at panicle maturity scored on a 1-9 scale where $1=$ actively growing and $9=$ dead 
optimal growth conditions many varieties flowered as early or earlier than in the field and all were earlier in seed ripening. Tiroler and Quartett flowered extremely rapidly in the greenhouse, suggesting the existence of specific gene sets for flower differentiation in these varieties. Furthermore, the difference between the time of flowering and harvest recorded in the two environments was substantially similar for US varieties, whereas for EU varieties an additional delay in seed formation and ripening was observed in the field. Overall, millet varieties showed a high plasticity in the control of the duration of both vegetative and reproductive stages. It should also be noted that, unlike US varieties and regardless of growth conditions, EU cultivars appeared to have already undergone senescence when the primary inflorescence reached maturity. It is widely recognized that days-to-flowering and days-to-maturation are important factors in determining the yield capacity of a cultivar (Calamai et al. $2020)$; despite late varieties are generally more productive, Zhang et al. (2019) suggested to limit the duration of the life cycle to 100-110 days during selection to favour millet insertion in crop rotation and reduce the risk of lodging. As shown in Table 6, all EU and US varieties on trial approached such limit, therefore the need to combine additional strategies for breeding high yielding lines can be anticipated.

\section{Yield potential}

Although proso millet is a valuable source of essential nutrients and nutraceuticals and a promising candidate to improve rotation in a context of global warming, its cultivation inside Western Europe is limited by the low productivity and the lack of dedicated equipment for downstream processing (Saleh et al. 2013). Millet breeding in developed countries has been limited and new varieties are perceived as essential elements for crop re-introduction in such territories. In previous work, attempts were made to identify associations between morpho-structural features and yield, with the ultimate objective to facilitate ideotype definition by breeders. Examining 364 millet germplasm accessions, Salini et al. (2010) found that seed yield per plant positively correlates with plant height and number of basal tillers; similarly, increased grain yields were observed when plant height, number of basal tillers, leaf length and width were higher in 200 accessions belonging to the ICRISAT germplasm collection (Vetriventhan and Upadhyaya 2018). A positive correlation between yield, height, number of basal tillers and leaf number was also recently reported by Calamai et al. (2020). Little information is however available as to the genetic potential exploitable by landraces and cultivars for yield, and how much of it is unexpressed or misused under stress conditions. In this study, all parameters in the greenhouse were set to be highly favourable for plant growth, therefore a good estimate of yield potential could be obtained for all varieties on trial (Table 7); five varieties, namely Sunup, Lisa, Huntsman, Quartett and Kornberger, were found significantly superior to the others, with a mean seed yield per plant close to $38 \mathrm{~g}$. Interestingly, these varieties were independently selected by European and US breeders and are characterized by different morphotypes. It appears therefore that further gains could be achieved by breeders by combining different elements affecting plant architecture, panicle shape and earliness in the absence of a reference model. Actually, the definition of a clear morphotype is hindered by the existence of interrelations of opposite sign between factors, as exemplified by Salini et al. (2010) for the triad seed yield, tiller number and daysto-flowering. On the other hand, the determination of yield potential of millet varieties revealed a huge gap in average seed production per plant at field level. Although the difference was evident in all cases, the cultivars with the highest yield potential were also the most productive in the field with the only exception being Kornberger (Fig. 1). This confirms that selection should focus more on adaptability to sub-optimal conditions and abiotic factors rather than a particular morphotype.

As far as yield components are concerned, seed loss from shattering was negligible in all varieties whereas 1000-seed weight varied significantly (Table 7); Tiroler was confirmed to be a small seeded variety together with Earlybird and Lisa. Even if in former times seed size was considered as a target for selection, no varieties with significantly larger seeds could be identified in the set on trial.

Table 7 Yield and yield components recorded under greenhouse conditions

\begin{tabular}{llll}
\hline & $\begin{array}{l}\text { Yield per plant } \\
(\mathbf{g})\end{array}$ & $\begin{array}{l}\mathbf{1} \text { K seed weight } \\
(\mathbf{g})\end{array}$ & $\begin{array}{l}\text { Loss from } \\
\text { shattering } \\
(\%)\end{array}$ \\
\hline Earlybird & $23.9^{\mathrm{c}}$ & $6.12^{\mathrm{a}}$ & 1.49 \\
GLRH16106 & $24.0^{\mathrm{c}}$ & $6.69^{\mathrm{a}}$ & 1.62 \\
Horizon & $23.0^{\mathrm{c}}$ & $7.22^{\mathrm{a}}$ & 0.88 \\
Huntsman & $36.6^{\mathrm{b}}$ & $6.80^{\mathrm{a}}$ & 2.92 \\
Jagna White & $13.9^{\mathrm{d}}$ & $6.54^{\mathrm{a}}$ & 1.56 \\
Kornberger & $34.6^{\mathrm{c}}$ & $6.45^{\mathrm{a}}$ & 1.19 \\
Lisa & $40.9^{\mathrm{a}}$ & $6.08^{\mathrm{a}}$ & 0.59 \\
Quartett & $34.8^{\mathrm{b}}$ & $6.50^{\mathrm{a}}$ & 2.03 \\
Sunrise & $21.9^{\mathrm{c}}$ & $6.64^{\mathrm{a}}$ & 1.32 \\
Sunup & $42.8^{\mathrm{a}}$ & $6.23^{\mathrm{a}}$ & 1.04 \\
Tiroler & $10.5^{\mathrm{d}}$ & $3.80^{\mathrm{b}}$ & 2.31 \\
\hline
\end{tabular}

Means with a letter in common do not statistically differ at $\mathrm{P}=0.05$ 


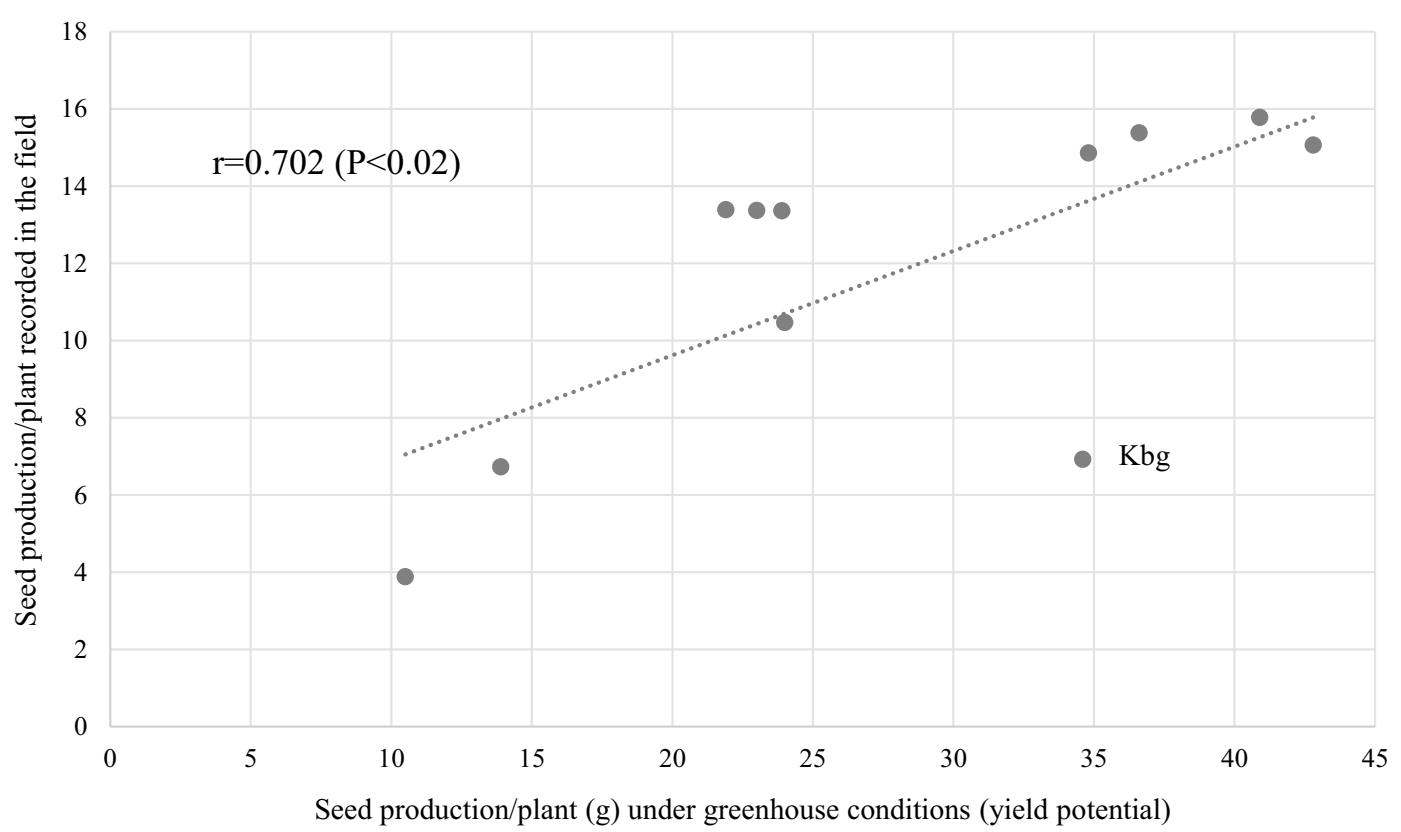

Fig. 1 Correlation between yield potential (estimated under controlled greenhouse conditions) and average seed production/plant recorded in the open field

\section{Other traits}

Both leaf and sheath pubescence differed in the variety set, but without a clear pattern. The degree of leaf and sheath pubescence did not correlate with each other, and big differences were found in favour of one or the other, depending on the variety considered. Notwithstanding this, the level of leaf and sheath pubescence was consistent among plants of the same variety, indicating that these traits can be exploited for variety discrimination, as formerly indicated by Vetriventhan and Upadhyaya (2018).

Among the remaining characters, little intervarietal variation was found and substantially confined to some EU cultivars. Lisa was the only variety with purplecoloured vegetative organs; it should be noted that this anthocyanin pigmentation developed under direct sunlight and not in the greenhouse. Differently from all other cultivars, Lisa also showed a purple apiculus, which was recognizable under both environmental conditions.

In respect to seed colour, an orange seed was characteristic of Tiroler, Lisa and Quartett, whereas all other cultivars had a uniformly ivory-white seed coat, in line with the current demand for light-coloured millet flour for human consumption (Das et al. 2019).

\section{SSR marker polymorphism and genetic metrics}

Under our lab conditions, the majority of SSR markers reported in the literature, although repeatedly tested, did not provide reliable outputs or evidence of polymorphism. In particular, none of the 46 markers indicated by $\mathrm{Hu}$ et al. (2009) were amplifiable at detectable levels. Among the 34 consistently amplifiable markers belonging to the series defined by Cho et al. (2010) and Hou et al. (2017), 22 were eventually discarded either because they proved monomorphic in our variety set, or were they indicative of a "fixed heterozygosity", an artifact caused by the allotetraploid nature of the species, in which two fixed homeologous loci are simultaneously amplified by a primer couple (Hunt et al. 2011; Flajšman et al. 2019).

After completion of the amplification trials, 12 selected markers (Table 3) were used to genotype 7-8 randomlychosen plants per variety. Despite the relatively low number of markers, each variety appeared characterized by a distinct allelic profile (available in Additional file 1). The number of alleles per locus ranged from two to six (average 2.64). As expected on the basis of the mating system of $P$. miliaceum, mostly relying on selfing, observed heterozygosity (Ho) was close to zero (Table 8). Genetic diversity and polymorphism information content (PIC) ranged from 0.01 to 0.67 (avg. 0.33) and from 0.01 to 0.61 (avg. 0.314), respectively (Table 8). PMM-014 was the least informative marker due to the widespread distribution of the major allele (0.99), a situation that did not occur with any other marker.

AMOVA was used to estimate and partition the total variance at two hierarchical levels viz. within and between populations uncovering higher levels of 
Table 8 Genetic metrics of 12 responsive SSR markers tested on the whole set of millet cultivars

\begin{tabular}{|c|c|c|c|c|c|c|c|c|}
\hline Marker & No. of obs & Alleles & Size range $b^{a}{ }^{a}$ & Genotypes & Ho & GD & PIC & MAF \\
\hline PMM-014 & 79 & 2 & $271-274$ & 2 & 0.01 & 0.01 & 0.01 & 0.99 \\
\hline PMM-023 & 79 & 5 & $205-215$ & 7 & 0.05 & 0.67 & 0.61 & 0.42 \\
\hline PMM-066b & 77 & 2 & $213-216$ & 2 & 0.00 & 0.23 & 0.20 & 0.87 \\
\hline PMM-073 & 79 & 4 & $268-280$ & 4 & 0.00 & 0.44 & 0.40 & 0.72 \\
\hline PMM-106 & 78 & 2 & $215-225$ & 2 & 0.00 & 0.31 & 0.26 & 0.81 \\
\hline PMM-115 & 80 & 3 & $253-263$ & 3 & 0.00 & 0.41 & 0.33 & 0.73 \\
\hline PMM-121 & 80 & 6 & $201-219$ & 6 & 0.00 & 0.55 & 0.52 & 0.64 \\
\hline PMM-126 & 78 & 3 & $251-257$ & 3 & 0.00 & 0.53 & 0.46 & 0.62 \\
\hline PMM-134 & 78 & 2 & $241-247$ & 2 & 0.00 & 0.40 & 0.32 & 0.72 \\
\hline SXAU032 B & 74 & 2 & 203-204 & 2 & 0.00 & 0.39 & 0.32 & 0.73 \\
\hline SXAU95 & 80 & 2 & $226-229$ & 2 & 0.00 & 0.16 & 0.15 & 0.91 \\
\hline SXAU227 B & 79 & 2 & $110-115$ & 2 & 0.00 & 0.49 & 0.37 & 0.58 \\
\hline Mean & 78.21 & 2.64 & & 2.78 & 0.00 & 0.33 & 0.28 & 0.77 \\
\hline
\end{tabular}

Ho observed heterozygosity, GD gene diversity, PIC polymorphism information content, MAF major allele frequency

${ }^{\text {a }}$ Fragment size does not include the 19-mer M13 tail

variation between $(72 \%)$ rather than within populations $(28 \%)$.

\section{Hierarchical and model based clustering}

Distance matrixes calculated with GenAlEx were eventually analysed with UPGMA to determine the genetic relationship among millet cultivars. Two welldefined clusters (A and B in Fig. 2) composed the final dendrogram: the former includes two subgroups, consisted of 5 US varieties and $3 \mathrm{EU}$ varieties, respectively, the latter the remaining EU varieties, namely Tiroler, Lisa and Quartett. The US varieties Huntsman, Sunup and Earlybird had the highest similarity coefficient of 1.00, as GL RH16106 with Jagna White. Such high similarity index (0.77-0.56) and clustering of the US varieties Huntsman, Earlybird, Sunup, and Sunrise were

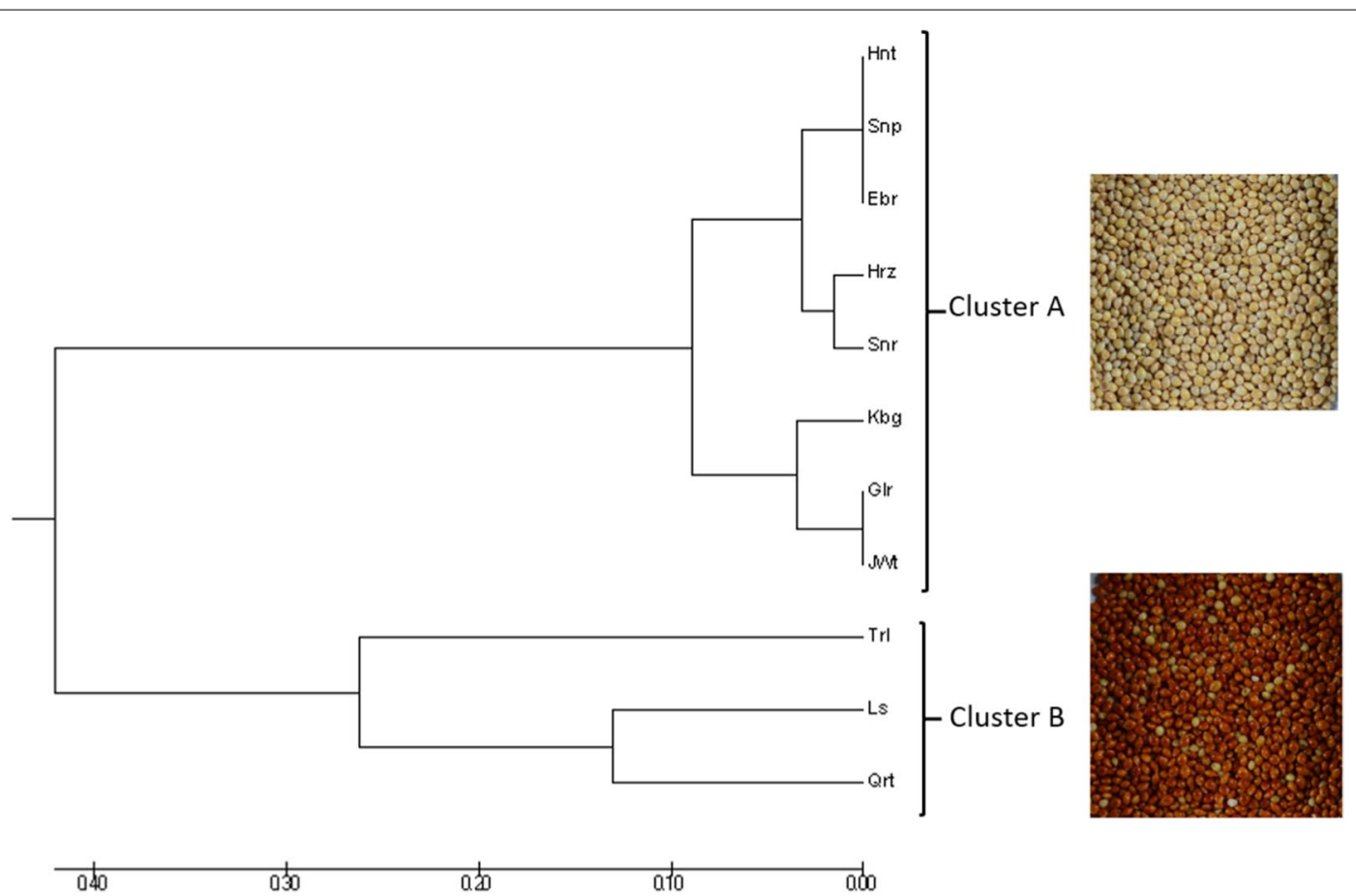

Fig. 2 Genetic relationships among the 11 P. miliaceum varieties as determined by UPGMA analysis 
also reported in earlier study based on 100 SSR markers and concerning genetic diversity of the US varieties (Rajput and Santra 2016). Interestingly, clusters A and B discriminate cultivars with a different seed coat colour and equally an alternative allele at locus SXAU032 B. Since such locus is derived from transcriptome sequencing data (Hou et al. 2017), some involvement of SXAU032 B in the synthesis of pigments can be hypothesized.

\section{Conclusions}

This study involved 11 cultivars that are currently grown in Eastern Europe and the US. Although they represent a reasonable sample of the seed assets available for millet cultivation in the EU, little was known about their inner genetic structure, adaptability, and genetic distance. In the attempt to solve these issues at least partly, a molecular characterization was performed leading to the following outcomes: (i) all cultivars are comparable to pure homozygous lines, therefore phenotypic variability pertains to the adaptability and structural plasticity of (essentially) single genotypes; (ii) significant genetic distances are observed between cultivars of different origin, suggesting that the discernment of artificial crosses can lead to enough genetic variability exploitable by breeders; (iii) results of SSR genotyping are in good agreement with the outcomes of morphological and physiological examination. The latter indicated that strong phenotypic differences are present among cultivars selected in different areas. Particularly, morphotypes varied a lot due to different tillering, leafiness, panicle exertion and plant height. Nevertheless, yields and yield potentials were found uncorrelated with any of these components, suggesting that during selection more efforts should be made in the improvement of adaptability and physiological efficiency, rather than the achievement of a specific plant architecture.

\section{Supplementary Information}

The online version contains supplementary material available at https://doi. org/10.1186/s43170-021-00047-6.

Additional file 1. Allelic profiles chracterizing the 11 varieties on trial.

\section{Acknowledgements}

I confirm that all authors have approved the manuscript for publication and that the content of the manuscript has not been published or submitted for publication elsewhere.

\section{Authors' contributions}

VM, ZN, PC, MS, and BM gathered morphological and molecular data. MS, VM, and $Z N$ wrote the manuscript. WJ and SD provided most of the tested varieties and together with BM edited the manuscript. All authors read and approved the final manuscript.

\section{Funding}

This study was supported by the European Union with the cross-border program Interreg V-A Italy-Austria 2014-2020 (project "RE-Cereal", ITAT 1005, P-7250-013-042) and set the basis for subsequent breeding activities designed to increase the yield and the nutritional value of millet flours.

\section{Availability of data and materials}

The datasets generated and/or analyzed during the current study are available in this published article and its additional information file.

\section{Declarations}

Ethics approval and consent to participate

Not applicable.

Consent for publication

Not applicable.

\section{Competing interests}

The authors declare that they have no competing of interests.

\section{Author details}

${ }^{1}$ Di4A, University of Udine, Via delle Scienze 206, 33100 Udine, Italy. ${ }^{2}$ Saatzucht Gleisdorf Ges.mbH, Am Tieberhof 33, 8200 Gleisdorf, Austria. ${ }^{3}$ Dept. of Agronomy and Horticulture, University of Nebraska-Lincoln, 4502 Ave I, Scottsbluff, NE 69361, USA.

Received: 28 January 2021 Accepted: 11 June 2021

Published online: 30 June 2021

\section{References}

Bandyopadhyay T, Muthamilarasan M, Prasad M. Millets for next generation climate-smart agriculture. Front Plant Sci. 2017;8:1266. https://doi.org/10. 3389/fpls.2017.01266

Boutin-Ganache I, Raposo M, Raymond M, Deschepper CF. M13-tailed primers improve the readability and usability of microsatellite analyses performed with two different allele-sizing methods. Biotechniques. 2001;31:24-8.

Calamai A, Masoni A, Marini L, Dellacqua M, Ganugi P, Boukail S, Benedettelli S, Palchetti E. Evaluation of the agronomic traits of 80 accessions of proso millet (Panicum miliaceum L.) under Mediterranean pedoclimatic conditions. Agriculture. 2020;10:578. https://doi.org/10.3390/agricultur e10120578.

Cho YI, Chung JW, Lee GA, Ma KH, Dixit A, Gwag JG, Park YJ. Development and characterization of twenty-five new polymorphic microsatellite markers in proso millet (Panicum miliaceum L.). Genes Genomics. 2010;32:267-73. https://doi.org/10.1007/s13258-010-0007-8.

Das S, Khound R, Santra M, Santra DK. Beyond bird feed: proso millet for human health and environment. Agriculture. 2019. https://doi.org/10. 3390/agriculture9030064.

Dwivedi SL, Van BETL, Ceccarelli S, Grando S, Upadhyaya HD, Ortiz R. Diversifying food systems in the pursuit of sustainable food production and healthy diets. Trends Plant Sci. 2017;22:842-56. https://doi.org/10.1016/j. tplants.2017.06.011.

Fanzo J, Hunter D, Borelli T, Mattei F. Diversifying food and diets. London: Routledge; 2013.

Flajšman M, Štajner N, Kocjan Ačko D. Genetic diversity and agronomic performance of Slovenian landraces of proso millet (Panicum miliaceum L.). Turk J Bot. 2019;11:185-95

Fukatsu E, Isoda K, Hirao T, Takahashi M, Watanabe A. Development and characterization of simple sequence repeat DNA markers for Zelkova serrata. Mol Ecol Notes. 2005;5(2):378-80. https://doi.org/10.1111/j.1471-8286. 2005.00933.x.

Gupta A, Sood S, Agrawal PK, Bhatt JC. Floral biology and pollination system in small millets. Eur J Plant Sci Biotechnol. 2012;6(2):80-6.

Habiyaremye C, Barth V, Highet K, Coffey T, Murphy KM. Phenotypic responses of twenty diverse proso millet (Panicum miliaceum L.) accessions to irrigation. Sustainability. 2017b;9:389. https://doi.org/10.3390/su9030389. 
Habiyaremye C, Matanguihan JB, Guedes JD, Ganjyal GM, Whiteman MR, Kidwell KK, Murphy KM. Proso millet (Panicum miliaceum L.) and its potential for cultivation in the pacific northwest, U.S.: a review. Front Plant Sci. 2017a;7:1-17. https://doi.org/10.3389/fpls.2016.01961.

Hou S, Sun Z, Li Y, Wang Y, Ling H, Xing G, Han Y, Li H. Transcriptomic analysis, genic SSR development, and genetic diversity of proso millet (Panicum miliaceum; Poaceae). Appl Plant Sci. 2017;5:1-11. https://doi.org/10.3732/ apps.1600137.

Hu X, Wang J, Lu P, Zhang H. Assessment of genetic diversity in broomcorn millet (Panicum miliaceum L.) using SSR markers. J Genet Genomics. 2009;36:491-500. https://doi.org/10.1016/S1673-8527(08)60139-3.

Hunt HV, Campana MG, Lawes MC, Park YJ, Bower MA, Hower CJ, Jones MK. Genetic diversity and phylogeography of broomcorn millet (Panicum miliaceum L.) across Eurasia. Mol Ecol. 2011;20:4756-71. https://doi.org/ 10.1111/j.1365-294X.2011.05318.X.

Hunt HV, Badakshi F, Romanova O, Howe CJ, Jones MK, Heslop-Harrison JS. Reticulate evolution in Panicum (Poaceae): the origin of broomcorn millet, P. miliaceum. J Exp Bot. 2014;65(12):3165-75. https://doi.org/10.1093/ jxb/eru161.

IBPGR. Descriptors for Panicum miliaceum and P sumatrense. Rome: International Board for Plant Genetic Resources; 1985. p. 1-14.

Kalinová J. Nutritionally important components of Proso millet (Panicum miliaceum L.). Food. 2007;1:91-100.

Kalinová J, Moudry J. Content and quality of protein in Proso millet (Panicum miliaceum L.) varieties. Plant Foods Hum Nutr. 2006;61:45-9. https://doi. org/10.1007/s11130-006-0013-9.

Klerkx L. Advisory services and transformation, plurality and disruption of agriculture and food systems: towards a new research agenda for agricultural education and extension studies. J Agric Educ Ext. 2020;26:131-40. https://doi.org/10.1080/1389224X.2020.1738046.

Liu K, Muse SV. PowerMarker: an integrated analysis environment for genetic marker analysis. Bioinform Appl Note. 2005;21:2128-9. https://doi.org/10. 1093/bioinformatics/bti282.

Lu H, Zhang J, Liu K, Wu N, Li Y, Zhou K, Ye M, Zhang T, Zhang H, Yang X, Shen L, Xu D, Li Q. Earliest domestication of common millet (Panicum miliaceum) in East Asia extended to 10,000 years ago. PNAS. 2009;106:7367-72.

Pathak H. Role of millets in nutritional security of India. Policy Paper 2013; 66, National Academy of Agricultural Sciences, New Delhi.

Peakall R, Smouse PE. GENALEX 6: genetic analysis in Excel. Population genetic software for teaching and research. Mol Ecol Notes. 2006;6(1):288-95. https://doi.org/10.1111/j.1471-8286.2005.01155.x.

Rai S, Kaur A, Chopra CS. Gluten-free products for celiac susceptible people. Front Nutr. 2018. https://doi.org/10.3389/fnut.2018.00116.

Rajput SG, Santra DK. Evaluation of genetic diversity of proso millet germplasm available in the United States using Simple-Sequence Repeat markers. Crop Sci. 2016;56:2401-9. https://doi.org/10.2135/cropsci2015. 10.0644.

Sage RF, Zhu XG. Exploiting the engine of C4 photosynthesis. J Exp Bot. 2011;62:2989-3000. https://doi.org/10.1093/jxb/err179.
Saleh ASM, Zhang Q, Chen J, Shen Q. Millet grains: nutritional quality, processing, and potential health benefits. Compr Rev Food Sci Food Saf. 2013;12:281-95.

Salini K, Nirmalakumari A, Muthiah AR, Senthil N. Evaluation of proso millet (Panicum miliaceum L.) germplasm collections. Electron J Plant Breed. 2010;1(4):489-99.

Saxena R, Vanga SK, Wang J, Orsat V, Raghavan V. Millets for food security in the context of climate change: a review. Sustainability. 2018;10:2228. https:// doi.org/10.3390/su10072228.

Schuelke M. An economic method for the fluorescent labeling of PCR fragments - a poor man's approach to genotyping for research and highthroughput diagnostics. Nat Biotechnol. 2000;18:1-2.

Seghatoleslami MJ, Kafi M, Majidi E. Effect of drought stress at different growth stages on yield and water use efficiency of five proso millet (Panicum miliaceum L.) genotypes. Pak J Bot. 2008;40:1427-32.

Tamura K, Stecher G, Peterson D, Filipski A, Kumar S. MEGA6: Molecular evolutionary genetics analysis version 6.0. Mol Biol Evol. 2013;30:2725-9. https://doi.org/10.1093/molbev/mst197.

Trivedi AK, Arya L, Verma M, Tyagi R. Genetic variability in proso millet (Panicum miliaceum) germplasm of Central Himalayan Region based on morphophysiological traits and molecular markers. Acta Physiol Plant. 2015. https://doi.org/10.1007/s11738-014-1770-y.

Upadhyaya HD, Sharma S, Gowda CLL, Reddy VG, Singh S. Developing proso millet (Panicum miliaceum L.) core collection using geographic and morpho-agronomic data. Crop Pasture Sci. 2011;62:383-9.

Vetriventhan M, Upadhyaya HD. Diversity and trait-specific sources for productivity and nutritional traits in the global proso millet (Panicum miliaceum L.) germplasm collection. Crop J. 2018;6:451-63. https://doi.org/10.1016/j. cj.2018.04.002.

Vieira MLC, Santini L, Diniz AL, Munhoz CDF. Microsatellite markers: what they mean and why they are so useful. Genet Mol Biol. 2016;39:312-28. https://doi.org/10.1590/1678-4685-GMB-2016-0027.

Yeh FC, Yang RC, Boyle TBJ, Ye ZH, Mao JX. POPGENE, the user-friendly shareware for population genetic analysis. Scienceopen. 1997.

Zhang D, Rabia BP, Liu J, Gong X, Liang J, Liu M, Lu P, Gao X, Feng B. Morphological diversity and correlation analysis of phenotypes and quality traits of proso millet (Panicum miliaceum L.) core collections. J Integr Agric. 2019;18(5):958-69.

Zou C, Li L, Miki D, Li D, Tang Q, Xiao L, Rajput S, Deng P, Peng L, Jia W, Huang R, Zhang M, Sun Y, Hu J, Fu X, Schnable PS, Chang Y, Li F, Zhang H, Feng B, Zhu X, Liu R, Schnable JC, Zhu JK, Zhang H. The genome of broomcorn millet. Nat Commun. 2019. https://doi.org/10.1038/s41467-019-08409-5.

\section{Publisher's Note}

Springer Nature remains neutral with regard to jurisdictional claims in published maps and institutional affiliations.
Ready to submit your research? Choose BMC and benefit from:

- fast, convenient online submission

- thorough peer review by experienced researchers in your field

- rapid publication on acceptance

- support for research data, including large and complex data types

- gold Open Access which fosters wider collaboration and increased citations

- maximum visibility for your research: over $100 \mathrm{M}$ website views per year

At BMC, research is always in progress.

Learn more biomedcentral.com/submissions 